\title{
Inter-Conversion between Different Compounds of Ternary Cs-Pb-Br System
}

\author{
Jing Li ${ }^{1,2}$, Huijie Zhang ${ }^{1}$, Song Wang ${ }^{3}$, Debing Long ${ }^{1}$, Mingkai Li ${ }^{1}$, Duofa Wang ${ }^{1,2,4,5, * \mathbb{C} \text { and }}$ \\ Tianjin Zhang ${ }^{1,2,4,5, *}$ \\ 1 Department of Materials Science and Engineering, Hubei University, Wuhan 430062, China; \\ lijing5781@hotmail.com (J.L.); huijie928@163.com (H.Z.); debinglong@foxmail.com (D.L.); \\ mingkailee@hotmail.com (M.L.) \\ 2 Hubei Collaborative Innovation Center for Advanced Organic Chemical Materials, Hubei University, \\ Wuhan 430062, China \\ 3 Hubei Key Laboratory of Low Dimensional Optoelectronic Materials and Devices, Hubei University of Arts \\ and Science, Xiangyang 441053, China; wangsong1984@126.com \\ 4 Hubei Provincial Key Laboratory of Polymers, Hubei University, Wuhan 430062, China \\ 5 Ministry of Education Key Laboratory of Green Preparation and Application for Materials, Hubei University, \\ Wuhan 430062, China \\ * Correspondence: duofawang@hotmail.com (D.W.); zhangtj@hubu.edu.cn (T.Z.); \\ Tel.: +86-27-8866-1729 (D.W. \& T.Z.)
}

Received: 1 April 2018; Accepted: 1 May 2018; Published: 2 May 2018

\begin{abstract}
The perovskite $\mathrm{CsPbBr}_{3}$ attracts great attention due to its potential in optoelectronics. However, stability remains a major obstacle to achieving its effecting application. In this work, we prepared $\mathrm{CsPbBr}_{3}$ solids through a simple reaction and investigated reversible conversion between $\mathrm{CsPbBr}_{3}, \mathrm{Cs}_{4} \mathrm{PbBr}_{6}$, and $\mathrm{CsPb}_{2} \mathrm{Br}_{5}$. We found that $\mathrm{CsPbBr}_{3}$ can be respectively converted to $\mathrm{Cs}_{4} \mathrm{PbBr}_{6}$ or $\mathrm{CsPb}_{2} \mathrm{Br}_{5}$ by reacting with $\mathrm{CsBr}$ or $\mathrm{PbBr}_{2}$. Thermodynamic analysis demonstrated that the chemical reactions above were exothermic and occurred spontaneously. Moreover, the formed $\mathrm{Cs}_{4} \mathrm{PbBr}_{6}$ could be converted to $\mathrm{CsPbBr}_{3}$ reversely, and then progressively converted to Cs-deficient $\mathrm{CsPb}_{2} \mathrm{Br}_{5}$ by extraction of $\mathrm{CsBr}$ with water. $\mathrm{The}_{\mathrm{CsPb}} \mathrm{Br}_{5}$ was converted to $\mathrm{CsPbBr}_{3}$ reversely under thermal annealing at $400{ }^{\circ} \mathrm{C}$. The thermodynamic processes of these conversions between the three compounds above were clarified. Our findings regarding the conversions not only provide a new method for controlled synthesis of the ternary $\mathrm{Cs}-\mathrm{Pb}-\mathrm{Br}$ materials but also clarify the underlying mechanism for the instability of perovskites $\mathrm{CsPbBr}_{3}$.
\end{abstract}

Keywords: $\mathrm{CsPbBr}_{3} ; \mathrm{Cs}_{4} \mathrm{PbBr}_{6} ; \mathrm{CsPb}_{2} \mathrm{Br}_{5} ;$ perovskite; conversion

\section{Introduction}

All-inorganic cesium lead halide perovskite $\mathrm{CsPbX}_{3}(\mathrm{X}=\mathrm{I}, \mathrm{Br}, \mathrm{Cl}$ ) nanocrystals (NCs) have attracted considerable attention owing to the outstanding photophysical properties, such as high photoluminescence quantum yields, narrow emission bandwidths, and tunable band gaps that covers the full visible range [1,2]. Since the pioneering work by the Kovalenko group in 2015, considerable progress in the preparation and application of $\mathrm{CsPbBr}_{3} \mathrm{NCs}$ has been achieved within a very short time period [1]. $\mathrm{CsPbBr}_{3} \mathrm{NCs}$ with a controllable morphology and composition have been fabricated by different methods, such as hot-injection [3], solvothermal synthesis [4], room-temperature precipitation [5], and chemical vapor deposition (CVD) [6]. Moreover, a variety of photoelectronic devices—such as photovoltaics [7], lasing [8], light-emitting diodes and photodetectors [9,10]—have been prepared from $\mathrm{CsPbBr}_{3} \mathrm{NC}$. In addition to $\mathrm{CsPbBr}_{3} \mathrm{NCs}$, other types of materials of the ternary $\mathrm{Cs}-\mathrm{Pb}-\mathrm{Br}$ system, such as $\mathrm{Cs}_{4} \mathrm{PbBr}_{6}$ and $\mathrm{CsPb}_{2} \mathrm{Br}_{5}$, have also been reported [11,12]. The compounds 
$\mathrm{CsPbBr}_{3}, \mathrm{Cs}_{4} \mathrm{PbBr}_{6}$, and $\mathrm{CsPb}_{2} \mathrm{Br}_{5}$ differ in the stacking of $\mathrm{PbBr}_{6}$ octahedra in their crystal structures. In $\mathrm{CsPbBr}_{3}$, the lead halide octahedra share all corners and are electronically coupled in three directions in space. However, in the $\mathrm{Cs}_{4} \mathrm{PbBr}_{6}$ lattice the octahedra do not share any corners [11]. One lead atom and eight bromine atoms make up a hendecahedron with edge sharing in $\mathrm{CsPb}_{2} \mathrm{Br}_{5}$ [12]. It is reasonable to suspect that the existence of multiple compounds of $\mathrm{Cs}-\mathrm{Pb}-\mathrm{Br}$ system is probably relevant to the unstable luminescent property of $\mathrm{CsPbBr}_{3}$, which is the main obstacle on the progress of $\mathrm{CsPbBr}_{3}$. The photoluminescence quantum yield (PLQY) of colloidal $\mathrm{CsPbBr}_{3} \mathrm{NCs}$ of $\sim 90 \%$ decreases dramatically to below $\sim 20 \%$ when they are in the solid phase (such as in a thin film). Different mechanisms have been proposed to explain the luminescence quenching, such as loss of the high quality of the NC by aggregation, removal of the surface passivation, and chemical decomposition of the materials $[11,13]$. Therefore, investigation on the inter-conversion between the $\mathrm{Cs}-\mathrm{Pb}-\mathrm{Br}$ compounds above is rather important.

Very recently, it has been reported that these ternary $\mathrm{Cs}-\mathrm{Pb}-\mathrm{Br}$ compounds can be inter-converted by physical and chemical treatments. Conversion of pre-synthesized $\mathrm{CsPbBr}_{3} \mathrm{NC}$ to $\mathrm{Cs}_{4} \mathrm{PbBr}_{6} \mathrm{NCs}$ have been reported by the extraction of $\mathrm{PbBr}_{2}$ through amine- and thiol-mediation method [14,15]. Furthermore, a reverse conversion from $\mathrm{Cs}_{4} \mathrm{PbBr}_{6}$ to $\mathrm{CsPbBr}_{3}$ has been reported by the Manna group through extraction of $\mathrm{CsBr}$ with Prussian Blue [16]. However, all the conversions above were performed on Cs-Pb-Br NCs with ligands on their surface and they were realized with mediation by a ligand. Investigations on the inter-conversion between the bare compounds of the $\mathrm{Cs}-\mathrm{Pb}-\mathrm{Br}$ system without ligand mediation are rarely reported, which is essential to reveal instability mechanism of $\mathrm{CsPbBr}_{3}$.

In this work, we prepared $\mathrm{CsPBr}_{3}$ particles without ligands through a simple low temperature method and realized reversible conversions between $\mathrm{CsPbBr}_{3}$ and $\mathrm{Cs}_{4} \mathrm{PbBr}_{6}$, and between $\mathrm{CsPbBr}_{3}$ and $\mathrm{CsPb}_{2} \mathrm{Br}_{5}$. We combined our experimental observations with calculations of the total energy of the three $\mathrm{Cs}-\mathrm{Pb}-\mathrm{Br}$ compounds, we found that conversions of $\mathrm{CsPbBr}_{3}$ to $\mathrm{Cs}_{4} \mathrm{PbBr}_{6}$ and to $\mathrm{CsPb}_{2} \mathrm{Br}_{5}$ could take place spontaneously. However, the reverse conversions required external intervention.

\section{Materials and Methods}

\subsection{Materials}

Lead(II) bromide ( $\mathrm{PbBr}_{2}$, Aladdin, 99.999\%), cesium bromide (CsBr, Aladdin, 99.999\%), hydrobromic acid ( $\mathrm{HBr}, \geq 40.0 \%$ ), and $\mathrm{N}, \mathrm{N}$-dimethylformamide (DMF, Aladdin, 99.9\%), were used without any further purification.

\subsection{Synthesis of $\mathrm{CsPbr}_{3}$}

The synthesis of $\mathrm{CsPbBr}_{3}$ was performed via a simple reaction and crystallization method. Briefly, $0.5 \mathrm{mmol}$ of $\mathrm{PbBr}_{2}$ and $0.5 \mathrm{mmol}$ of $\mathrm{CsBr}$ were dissolved in $10 \mathrm{~mL}$ of DMF and stirred until completely dissolved. The mixture was then placed in an oven at $40{ }^{\circ} \mathrm{C}$ to evaporate the solvent and induce the reaction to produce $\mathrm{CsPbBr}$ solids.

\subsection{Experiments on the Inter-Conversion between the Compounds}

\subsubsection{Forward Conversion from $\mathrm{CsPbBr}_{3}$ to $\mathrm{Cs}_{4} \mathrm{PbBr}_{6}$ or $\mathrm{CsPb}_{2} \mathrm{Br}_{5}$}

Cesium bromide ( $\mathrm{CsBr}, 3 \mathrm{mmol})$ was first dissolved in hydrobromic acid $(\mathrm{HBr}, 2 \mathrm{~mL})$. Pre-synthesized $\mathrm{CsPbBr}_{3}(1 \mathrm{mmol})$ was added to the solution and stirred to react with $\mathrm{CsBr}$ and produce $\mathrm{Cs}_{4} \mathrm{PbBr}_{6}$, which precipitated at the bottom of the mixture. The precipitate was collected by evaporating the $\mathrm{HBr}$ solvent. For the conversion to $\mathrm{CsPb}_{2} \mathrm{Br}_{5}$, lead(II) bromide ( $\left.\mathrm{PbBr}_{2}, 1 \mathrm{mmol}\right)$ was first dissolved in hydrobromic acid $\left(\mathrm{HBr}, 2 \mathrm{~mL}\right.$ ). Then the $\mathrm{CsPbBr}_{3}$ solid (1 mmol) was added to the solution with stirring to react with $\mathrm{PbBr}_{2}$. The $\mathrm{CsPb}_{2} \mathrm{Br}_{5}$ was produced and precipitated at the bottom of the mixture. The precipitate was collected by evaporating the $\mathrm{HBr}$ solvent. 


\subsubsection{Reverse Conversion from $\mathrm{Cs}_{4} \mathrm{PbBr}_{6}$ or $\mathrm{CsPb}_{2} \mathrm{Br}_{5}$ to $\mathrm{CsPbBr}_{3}$}

A $0.25 \mathrm{mmol}$ portion of $\mathrm{Cs}_{4} \mathrm{PbBr}_{6}$ was added to de-ionized water $(1 \mathrm{~mL})$ and stirred, to trigger the reverse conversion from $\mathrm{Cs}_{4} \mathrm{PbBr}_{6}$ to $\mathrm{CsPbBr}_{3}$. The conversion of $\mathrm{CsPb}_{2} \mathrm{Br}_{5}$ to $\mathrm{CsPbBr}_{3}$ was conducted by annealing the $\mathrm{CsPb}_{2} \mathrm{Br}_{5}$ solids for $4 \mathrm{~h}$ at $400{ }^{\circ} \mathrm{C}$ in air.

\subsection{Materials Characterization}

Crystal structures were measured with an X-ray diffractometer (Bruker D8 Advance, Karlsruhe, Baden-Wurttemberg, Germany) with Cu-Ka radiation $(\lambda=1.5406 \AA)$. Scanning electron microscope (SEM) and energy dispersive spectrum (EDS) measurements were performed on a JSM7100F, Tokyo, Honshu, Japan. A transmission electron microscope (TEM) (FEI; Tecnai-G20 and 200 kV, Hillsboro, OR, USA) was used to characterize the microstructure of the $\mathrm{CsPbBr}_{3}, \mathrm{Cs}_{4} \mathrm{PbBr}_{6}$ and $\mathrm{CsPb}_{2} \mathrm{Br}_{5}$. Absorption spectra were measured on a UV-Visible-NIR spectrophotometer (SHIMADZU UV-3600, Kyoto, Honshu, Japan).

\subsection{First-Principle Calculations}

First-principle calculations were performed on the basis of density functional theory (DFT) as implemented in the QUANTUM ESPRESSO (QE) code. The exchange and correlation terms were described using the general gradient approximation (GGA) of Perdew-Burke-Ernzerhof (PBE). The energy cutoff for the plane wave basis set was $600 \mathrm{eV}$. The accuracy of the self-consistent field (SCF) energy convergence and the convergence accuracy of the internal stress of the crystal were less than $1.4 \times 10^{-5} \mathrm{eV} /$ atom and $0.05 \mathrm{Gpa}$, respectively. For the different alloy configurations, Monkhorst-Pack grids were determined automatically for the Brillouin zone integration and the KPPRA parameter was set to be 1000 .

\section{Results and Discussion}

\subsection{Synthesis of $\mathrm{Cs}_{s} \mathrm{PBr}_{3}$ and Forward Conversion to $\mathrm{Cs}_{4} \mathrm{PbBr}_{6}$ and $\mathrm{CsPb}_{2} \mathrm{Br}_{5}$.}

Synthesis of $\mathrm{CsPbBr}_{3}$ (PDF\#18-0364) was performed via a simple reaction and crystallization method without the use of any ligands. Full details are described in the experimental section. Characterization results of the prepared solids by XRD and absorption spectroscopy, shown in Figure 1a,b, demonstrated that the product was pure monoclinic $\mathrm{Cs} \mathrm{PbBr}_{3}$.

The as-synthesized $\mathrm{CsPbBr}_{3}$ solids were used to perform the forward conversion from $\mathrm{CsPbBr}_{3}$ to $\mathrm{Cs}_{4} \mathrm{PbBr}_{6}$ and $\mathrm{CsPb}_{2} \mathrm{Br}_{5}$. First, $\mathrm{CsBr}$ was dissolved in $\mathrm{HBr}$, and a certain amount of the $\mathrm{CsPbBr}_{3}$ solid synthesized above (yellow) was added into the solution $\left(\mathrm{CsPbBr}_{3} / \mathrm{CsBr}=1: 3\right.$, mole ratio) with stirring. This approach ensured that only $\mathrm{H}$ was introduced into the reaction system, containing $\mathrm{Cs}$, $\mathrm{Pb}$, and $\mathrm{Br}$, which simplified the analysis on the reaction. After stirring for several hours, a white precipitate formed, which was revealed to be rhombohedral $\mathrm{Cs}_{4} \mathrm{PbBr}_{6}$ by $\mathrm{XRD}$, as shown in Figure 1c. To reveal whether $\mathrm{CsPbBr}_{3}$ remnants exist in the product since both $\mathrm{CsPbBr}_{3}$ and $\mathrm{Cs}_{4} \mathrm{PbBr}_{6}$ exhibit diffraction peaks near $27^{\circ}$, the absorption spectrum of $\mathrm{Cs}_{4} \mathrm{PbBr}_{6}$ product was measured and is shown in Figure 1d. A typical absorption peak at $315 \mathrm{~nm}$ was observed, which is characteristic of $\mathrm{Cs}_{4} \mathrm{PbBr}_{6}$, and no absorption peaks corresponding to $\mathrm{CsPbBr}_{3}$ appear [17]. This result further confirmed the conversion from $\mathrm{CsPbBr}_{3}$ to $\mathrm{Cs}_{4} \mathrm{PbBr}_{6}$. As far as the additional small diffraction peak near $29^{\circ}$ denoted by purple dot in Figure $1 \mathrm{c}$ is concerned, it corresponds to CsBr. Because the ratio of the reactants $\mathrm{CsPbBr}_{3} / \mathrm{CsBr}$ was 1:3 and the only product was $\mathrm{Cs}_{4} \mathrm{PbBr}_{6}$, Equation (1) is proposed to describe the chemical reaction of the conversion. Except for operating as the solvent, the $\mathrm{HBr}$ also supplies abundance of $\mathrm{Br}^{+}$and promotes the chemical reaction according to Equation (1).

$$
\mathrm{CsPbBr}_{3}+3 \mathrm{CsBr}=\mathrm{Cs}_{4} \mathrm{PbBr}_{6}
$$


The conversion from $\mathrm{CsPbBr}$ to $\mathrm{CsPb}_{2} \mathrm{Br}_{5}$ was realized by a similar reaction. First, $\mathrm{PbBr}_{2}$ was dissolved in $\mathrm{HBr}$ and $\mathrm{CsPbBr}$ solid was added into the solution $\left(\mathrm{CsPbBr}_{3} / \mathrm{PbBr}_{2}=1: 1\right.$, mole ratio). After several hours, white solids precipitated at the bottom of the mixture. XRD characterization, as shown in Figure 1e, of the precipitate revealed that it was pure tetragonal $\mathrm{CsPb}_{2} \mathrm{Br}_{5}$, indicating that the conversion from $\mathrm{CsPbBr}_{3}$ to $\mathrm{CsPb}_{2} \mathrm{Br}_{5}$ occurred. To confirm the conversion, the absorption spectra of the reactant and product were measured. As shown in Figure 1f, the absorption edge moved to $380 \mathrm{~nm}$, indicating that $\mathrm{CsPbBr}_{3}$ was converted into $\mathrm{CsPb}_{2} \mathrm{Br}_{5}$. The conversion was believed to occur through Equation (2), as shown below, based on the fact that the ratio of the reactants $\mathrm{CsPbBr} 3 / \mathrm{PbBr}_{2}$ was $1: 1$ and the only product formed was $\mathrm{CsPb}_{2} \mathrm{Br}_{5}$.

$$
\mathrm{CsPbr}_{3}+\mathrm{PbBr}_{2}=\mathrm{CsPb}_{2} \mathrm{Br}_{5}
$$
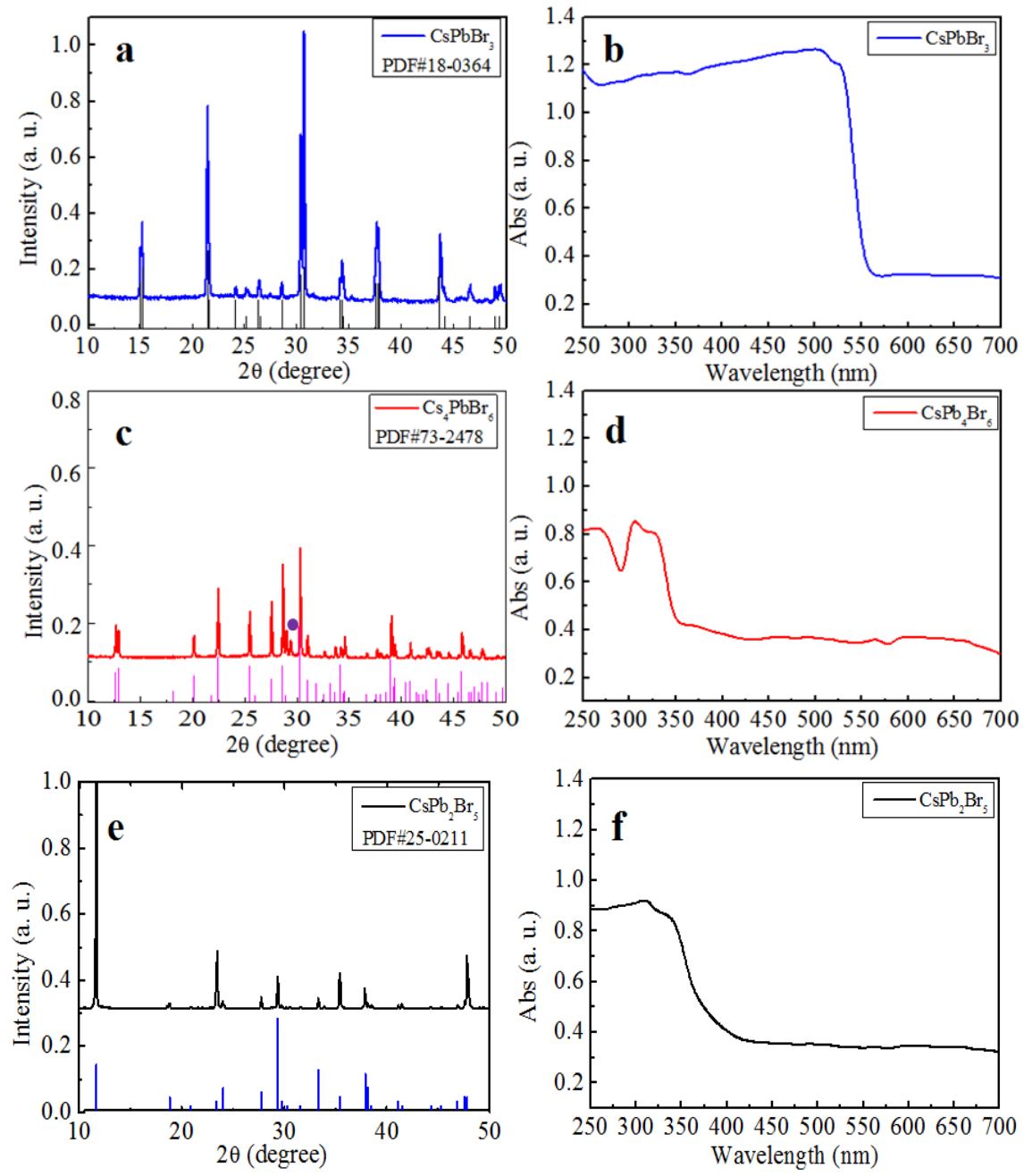

Figure 1. The $\mathrm{XRD}$ pattern of (a) $\mathrm{CsPbBr}_{3}$, (c) $\mathrm{Cs}_{4} \mathrm{PbBr}_{6}$ and (e) $\mathrm{CsPb}_{2} \mathrm{Br}_{5}$. The absorption spectra of (b) $\mathrm{CsPbBr}_{3}$, (d) $\mathrm{Cs}_{4} \mathrm{PbBr}_{6}$, and (f) $\mathrm{CsPb}_{2} \mathrm{Br}_{5}$.

The morphology of each material was examined by scanning electron microscope (SEM) imaging, as shown in Figure S1. Energy dispersive spectroscopy (EDS) results, also shown in Figure S1, indicated that the molar ratios of $\mathrm{Cs} / \mathrm{Pb} / \mathrm{Br}$ were $1.18 / 1 / 2.89,1 / 1.87 / 5.57$, and 4.18/1/6.36 respectively, which agreed well with the stoichiometries of $\mathrm{CsPbBr}_{3}, \mathrm{CsPb}_{2} \mathrm{Br}_{5}$, and $\mathrm{Cs}_{4} \mathrm{PbBr}_{6}$. The microstructure of each Cs-Pb-Br ternary compound was characterized by high resolution TEM (HRTEM), as shown in Figure 2. Well-resolved lattice fringes were observed in the HRTEM images. In Figure 2b, the separation between 
the fringes was $0.588 \mathrm{~nm}$, which corresponded to the (001) plane of $\mathrm{CsPbBr}_{3}$. In the HRTEM images of $\mathrm{CsPb}_{2} \mathrm{Br}_{5}$ and $\mathrm{Cs}_{4} \mathrm{PbBr}_{6}$, the (110) and (220) planes were clearly observed, with lattice separations of 0.609 and $0.451 \mathrm{~nm}$, respectively. These EDS and HRTEM results further confirmed that the conversions had occurred.
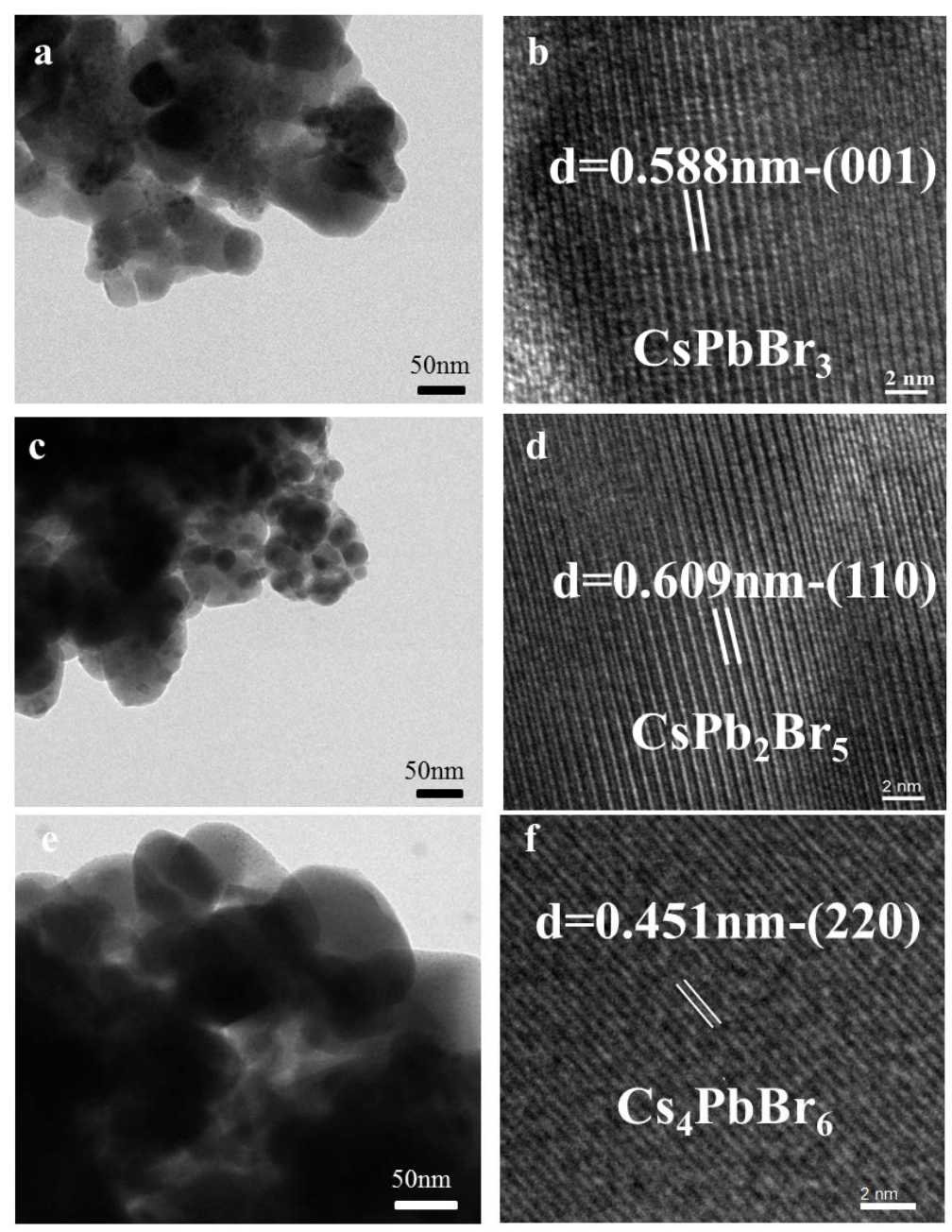

Figure 2. (a,c,e) TEM images; and (b,d,f) high-resolution lattice resolved TEM images of a representative $\mathrm{CsPbBr}_{3}, \mathrm{CsPb}_{2} \mathrm{Br}_{5}$, and $\mathrm{Cs}_{4} \mathrm{PbBr}_{6}$, respectively.

In the conversions above, we did not use high temperature, high pressure or a catalyst to trigger the reactions. Hence, the Equations (1) and (2) are thermodynamically controlled process and the driving force, described by the free energy should be negative. Therefore, we calculated the total energy (Et) of the Equations (1) and (2) by first principles. The changes of the total energy $(\Delta \mathrm{Et})$ for Equations (1) and (2) were $-9508.07 \mathrm{eV}$ and $-15019.13 \mathrm{eV}$, respectively, indicating that the chemical reactions were exothermic and could occur spontaneously. The total energy of each materials is shown in Table S1 in the supporting information. These results explain why this simple method can successfully realize the conversion of $\mathrm{CsPbr}_{3}$ into $\mathrm{Cs}_{4} \mathrm{PbBr}_{6}$ or $\mathrm{CsPb}_{2} \mathrm{Br}_{5}$.

\subsection{Reverse Conversion by Water Extraction and Thermal Annealing}

For the reverse conversion from $\mathrm{Cs}_{4} \mathrm{PbBr}_{6}$ to $\mathrm{CsPbBr}_{3}$, we used the water extraction method proposed by the Sun group [18]. By mixing a $\mathrm{Cs}_{4} \mathrm{PbBr}_{6}$ quantum dot dispersion in nonpolar hexane with water, Sun et al. found that $\mathrm{CsBr}$ could be extracted from $\mathrm{Cs}_{4} \mathrm{PbBr}_{6}$ owing to the high solubility of $\mathrm{CsBr}$ in water. This effect led to a conversion from $\mathrm{Cs}_{4} \mathrm{PbBr}_{6}$ to $\mathrm{CsPbBr}_{3}$. 
Here, we found that water could also extract $\mathrm{CsBr}$ from $\mathrm{Cs}_{4} \mathrm{PbBr}_{6}$ solids without ligands on their surface. However, the reaction we observed was much more vigorous and quick. These differences between our observations and those of Sun et al. could be attributed to the absence of protective ligands on the surface of our NCs, unlike the $\mathrm{Cs}_{4} \mathrm{PbBr}_{6}$ quantum dot dispersion reported by Sun [18]. When the $\mathrm{Cs}_{4} \mathrm{PbBr}_{6}$ solids were added into deionized water, the color of the precipitate changed to yellow immediately, and returned to white again over a longer time, suggesting that chemical reactions occurred in two stages. The precipitate at different stages was removed from the deionized water and the composition was measured by XRD.

As shown in Figure 3a, most of the $\mathrm{Cs}_{4} \mathrm{PbBr}_{6}$ transformed to $\mathrm{CsPbBr}_{3}$ within 1 min. However, $\mathrm{CsPbBr}_{3}$ was not the final product. The conversion into $\mathrm{CsPb}_{2} \mathrm{Br}_{5}$ proceeded within $5 \mathrm{~min}$, and the major product was $\mathrm{CsPb}_{2} \mathrm{Br}_{5}$ after $1 \mathrm{~h}$. Therefore, we suggest that the water not only extracted $\mathrm{CsBr}$ from $\mathrm{Cs}_{4} \mathrm{PbBr}_{6}$, but also extracted $\mathrm{CsBr}$ from $\mathrm{CsPbBr}_{3}$ to produce $\mathrm{CsPb}_{2} \mathrm{Br}_{5}$. The composition of the solution was also investigated to clarify the nature of the chemical transformation. To confirm the water extraction mechanism for the conversions, we evaporated the water and performed XRD measurements on the solid obtained, which was determined to be $\mathrm{CsBr}$, as shown in the supporting information Figure S2. Therefore, we propose the following Equations for the chemical reactions occurring at each stage of the transformation as:

$$
\begin{aligned}
& \mathrm{Cs}_{4} \mathrm{PbBr}_{6}=\mathrm{CsPbBr}_{3}+3 \mathrm{CsBr}, \\
& 2 \mathrm{CsPbBr}_{3}=\mathrm{CsPb}_{2} \mathrm{Br}_{5}+\mathrm{CsBr}
\end{aligned}
$$

Figure $3 \mathrm{~b}$ shows the absorption spectrum measured from the precipitate samples removed from deionized water after different reaction times. A strong characteristic absorption edge at $560 \mathrm{~nm}$ appeared after $1 \mathrm{~min}$ and its intensity decreased at longer reaction times. This result indicates that the $\mathrm{CsPbBr} 3$ was produced within 1 min and converted to $\mathrm{CsPb}_{2} \mathrm{Br}_{5}$ over longer reaction times. These findings are consistent with the XRD results.
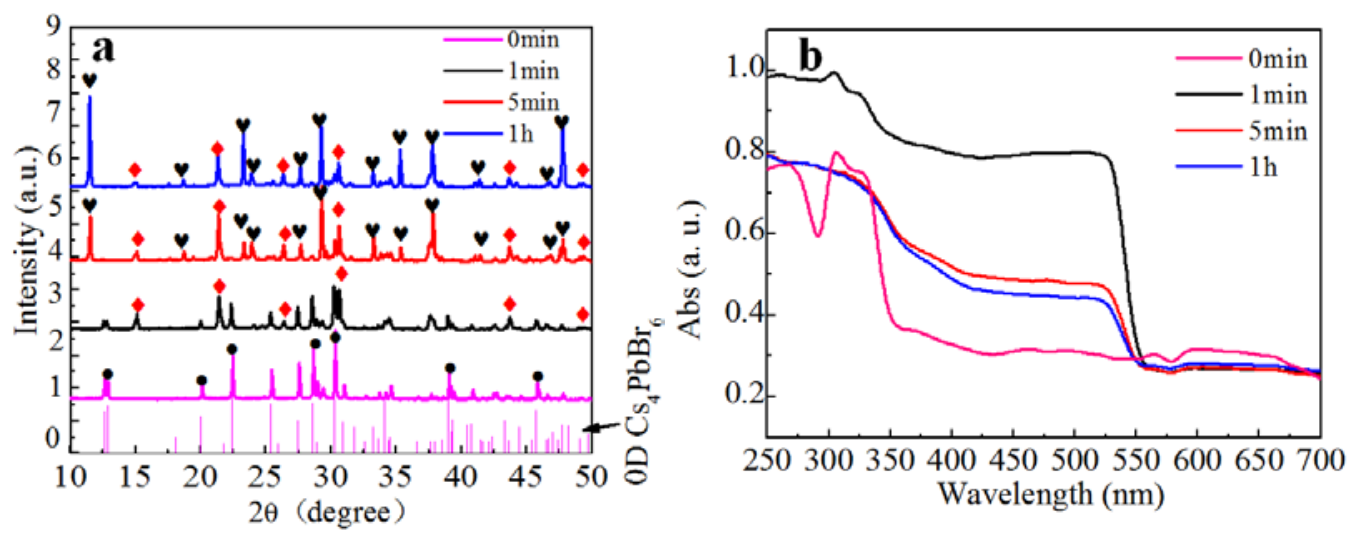

Figure 3. (a) PXRD pattern of $\mathrm{Cs}_{4} \mathrm{PbBr}_{6}$ solids after water treatment for different time, the red diamonds represent $\mathrm{CsPBr}_{3}$, the black hearts represents $\mathrm{CsPb}_{2} \mathrm{Br}_{5}$, the black dots represents $\mathrm{Cs}_{4} \mathrm{PbBr}_{6}$; (b) Absorption spectra of PXRD pattern of $\mathrm{Cs}_{4} \mathrm{PbBr}_{6}$ solids after water treatment for different times.

To confirm the two-step transformation model suggested above, we added pure $\mathrm{CsPbBr}_{3}$ into deionized water and investigated the conversion. We found that the transformation in Equation (4) occurred and a white precipitate was formed quickly. As shown in the XRD pattern obtained from the precipitate in Figure 4a, the diffraction peaks related to $\mathrm{CsPbBr}_{3}$ became weak and strong diffraction peaks corresponding to $\mathrm{CsPb}_{2} \mathrm{Br}_{5}$ were observed after $1 \mathrm{~min}$. Moreover, the intensity of $\mathrm{CsPb}_{2} \mathrm{Br}_{5}$ gradually increased as the reaction progressed. The absorption spectra in Figure $4 \mathrm{~b}$, show that the absorption peak at $560 \mathrm{~nm}$ from $\mathrm{CsPbBr}_{3}$ became progressively weaker. We note that the absorption 
peak of $\mathrm{CsPbBr}_{3}$ did not completely disappear, even after $1 \mathrm{~h}$ of reaction, indicating that a small amount of $\mathrm{CsPbBr}_{3}$ persisted. The XRD and absorption results clearly demonstrated that $\mathrm{CsPbBr}$ could be converted to $\mathrm{CsPb}_{2} \mathrm{Br}_{5}$ through extraction of $\mathrm{CsBr}$ by water. The conversion induced by water extraction is undoubtedly one of the reasons leading to the unstable luminescent property of $\mathrm{CsPbBr}_{3}$. The water vapor in the air can extract $\mathrm{CsBr}$ from $\mathrm{CsPbBr}_{3}$ and trigger the conversion into $\mathrm{CsPb}_{2} \mathrm{Br}_{5}$, which subsequently results in the degradation of luminescence.
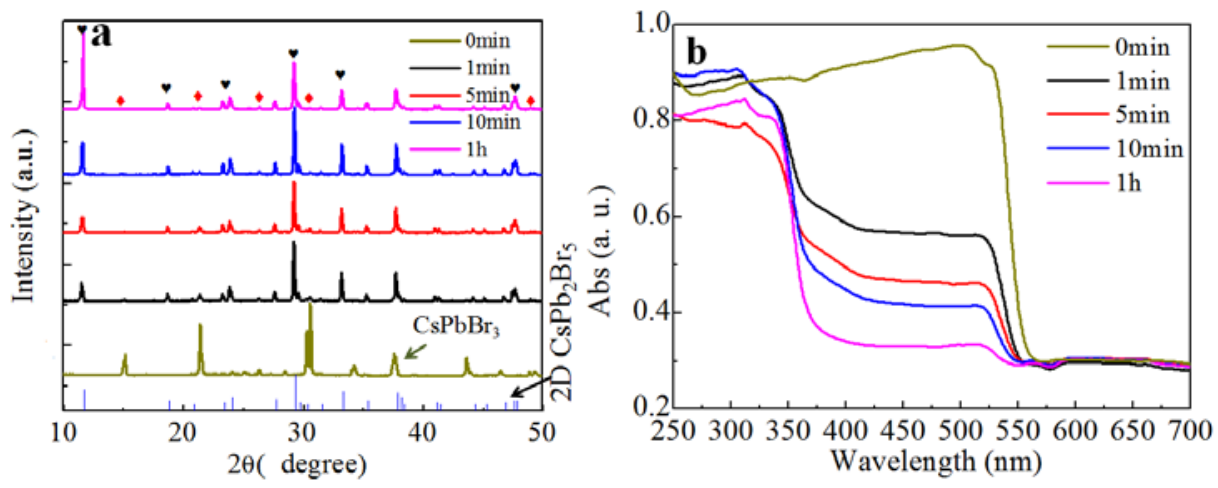

Figure 4. (a) XRD patterns and (b) absorption spectra of $\mathrm{CsPbBr}_{3}$ solids after water treatment for different times. Red diamonds represent $\mathrm{CsPbBr}_{3}$ and black hearts denote the diffraction peaks of $\mathrm{CsPb}_{2} \mathrm{Br}_{5}$.

We realized a conversion from $\mathrm{CsPb}_{2} \mathrm{Br}_{5}$ to $\mathrm{CsPbBr}_{3}$, using a previously reported annealing method [19]. We annealed the $\mathrm{CsPb}_{2} \mathrm{Br}_{5}$ solids at $400{ }^{\circ} \mathrm{C}$ in air for $4 \mathrm{~h}$ and monitored the associated $\mathrm{XRD}$ and absorption properties. Figure $5 \mathrm{a}$ shows $\mathrm{XRD}$ data of the $\mathrm{CsPb_{2 }} \mathrm{Br}_{5}$ before and after annealing. The corresponding diffraction peaks before annealing were indexed to $\mathrm{CsPb}_{2} \mathrm{Br}_{5}$. After annealing, the main product corresponded to $\mathrm{CsPbBr}_{3}$ and $\mathrm{PbBr}_{2}$, and a small amount of $\mathrm{CsPb}_{2} \mathrm{Br}_{5}$ remained. The decomposition is depicted by the Equation:

$$
\mathrm{CsPb}_{2} \mathrm{Br}_{5}=\mathrm{CsPbBr}_{3}+\mathrm{PbBr}_{2}
$$

The absorption spectra in Figure $5 b$ show that the absorption peak relevant to $\mathrm{Cs} \mathrm{PbBr}_{3}$ was considerably enhanced, indicating the generation of $\mathrm{CsPbBr}_{3}$, which is consistent with the XRD results shown in Figure 5a. As far as the mechanism of the Equation (5) is concerned, it is ascribed to the decompositon of $\mathrm{CsPb}_{2} \mathrm{Br}_{5}$ energetically driven by high temperature annealing.
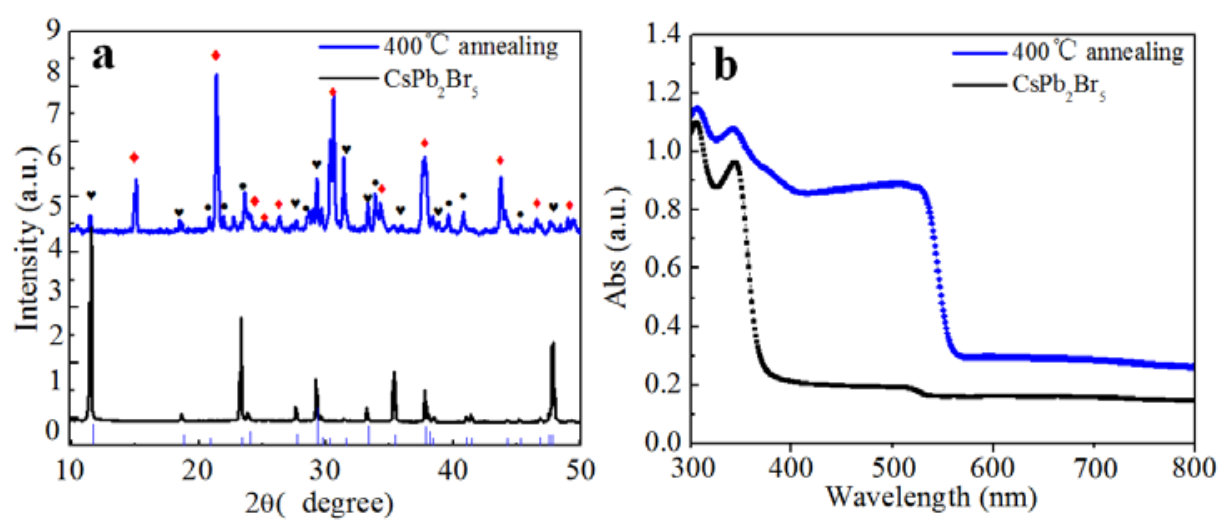

Figure 5. (a) $\mathrm{XRD}$ pattern, and (b) absorption spectra of $\mathrm{CsPb}_{2} \mathrm{Br}_{5}$ particles after annealing at $400{ }^{\circ} \mathrm{C}$ temperature. In the XRD pattern, the red diamonds denotes the diffraction peak of $\mathrm{CsPbBr}_{3}$, the black dots denotes the diffraction peak of $\mathrm{PbBr}_{2}$ and black hearts denote the diffraction peaks of $\mathrm{CsPb}_{2} \mathrm{Br}_{5}$. 


\section{Conclusions}

In conclusion, we examined a reversible conversion between $\mathrm{CsPbBr}_{3}, \mathrm{Cs}_{4} \mathrm{PbBr}_{6}$, and $\mathrm{CsPb}_{2} \mathrm{Br}_{5}$. First, $\mathrm{CsPbBr}_{3}$ solids were synthesized through a simple reaction of $\mathrm{CsBr}$ and $\mathrm{PbBr}_{2}$ in $\mathrm{HBr}$. Addition of the prepared $\mathrm{CsPbBr}_{3}$ solids into the $\mathrm{CsBr} / \mathrm{PbBr}_{2}$ solution in $\mathrm{HBr}$, resulted in its conversion into $\mathrm{Cs}_{4} \mathrm{PbBr}_{6}$ and $\mathrm{CsPb}_{2} \mathrm{Br}_{5}$, through Equations (1) and (2), respectively. Thermodynamic analysis revealed that the transformations above were exothermic and occurred spontaneously. Moreover, we found that when added into the water $\mathrm{Cs}_{4} \mathrm{PbBr}_{6}$ converted to $\mathrm{CsPbBr}$ first, and then to Cs-deficient $\mathrm{CsPb}_{2} \mathrm{Br}_{5}$. These results are attributed to the ionic nature of the $\mathrm{Cs}-\mathrm{Pb}-\mathrm{Br}$ system and the high solubility of $\mathrm{CsBr}$ in water, which led to extraction of $\mathrm{CsBr}$ by water. The $\mathrm{CsPb}_{2} \mathrm{Br}_{5}$ was converted to $\mathrm{CsPbBr}_{3}$ through thermal annealing at $400{ }^{\circ} \mathrm{C}$. Our results on the inter-conversion of the $\mathrm{Cs}-\mathrm{Pb}$ - $\mathrm{Br}$ compounds sheds a light on understanding the mechanism and developing new solutions for the instability problem of the $\mathrm{Cs}-\mathrm{Pb}$-Br compounds. Moreover, it supplies important information on the controllable preparation of the $\mathrm{Cs}-\mathrm{Pb}-\mathrm{Br}$ materials.

Supplementary Materials: The following are available online at http:/ / www.mdpi.com/1996-1944/11/5/717/s1, Figure S1: Scanning electron microscope (SEM) and Energy dispersive X-spectroscopy (EDS); Figure S2: The XRD pattern of CsBr (PDF\#73-0391) obtained from the solvent of water by evaporation; Table S1. The total energy of each materials is calculated based on the optimized structure using DFT.

Author Contributions: J.L., H.Z., and S.W. performed the experiments; D.L. and M.L. performed the calculation; D.W. and T.Z. design this study and analyzed the data; all authors read and approved the final manuscript.

Funding: This research was funded by National Natural Science Foundation of China (nos. 11174071, 11304088 and 51372180) and Special Technical Innovation Project of Hubei Province (no. 2016AAA035).

Acknowledgments: We thank Zhijun Ma in Hubei University for his help on the XRD measurement and analysis.

Conflicts of Interest: The authors declare no conflicts of interest.

\section{References}

1. Zhang, J.; Yang, Y.; Deng, H.; Farooq, U.; Yang, X.K.; Kan, J.; Tang, J.; Song, H.S. High quantum yield blue emission from lead-free inorganic antimony halide perovskite colloidal quantum dot. ACS Nano 2017, 11, 9294-9302. [CrossRef] [PubMed]

2. Protesescu, L.; Yakunin, S.; Bodnarchuk, M.I.; Krieg, F.; Caputo, R.; Hendon, C.H.; Yang, R.X.; Walsh, A.; Kovalenko, M.V. Nanocrystals of cesium lead halide perovskites $\left(\mathrm{CsPbX}_{3}, \mathrm{X}=\mathrm{Cl}, \mathrm{Br}\right.$, and I): novel optoelectronic materials showing bright emission with wide color gamut. Nano Lett. 2015, 15, 3692-3696. [CrossRef] [PubMed]

3. Pan, A.; He, B.; Fan, X.; Liu, Z.; Urban, J.J.; Alivisatos, A.P.; He, L.; Liu, Y. Insight into the ligand-mediated synthesis of colloidal $\mathrm{CsPbr}_{3}$ perovskite nanocrystals: the role of organic acid, base, and cesium precursors. ACS Nano 2016, 10, 7943-7954. [CrossRef] [PubMed]

4. Rakita, Y.; Kedem, N.; Gupta, S.; Sadhanala, A.; Kalchenko, V.; Böhm, M.L.; Kulbak, M.; Friend, R.H.; Cahen, D.; Hodes, G. Low-temperature solution-grown $\mathrm{CsPbBr}_{3}$ single crystals and their characterization. Cryst. Growth Des. 2016, 16, 5717-5725. [CrossRef]

5. Sun, S.; Yuan, D.; Xu, Y.; Wang, A.; Deng, Z. Ligand-mediated synthesis of shape-controlled cesium lead halide perovskite nanocrystals via reprecipitation process at room temperature. ACS Nano 2016, 10, 3648-3657. [CrossRef] [PubMed]

6. Wang, Y.; Guan, X.; Li, D.; Cheng, H.-C.; Duan, X.; Lin, Z.; Duan, X. Chemical vapor deposition growth of single-crystalline cesium lead halide microplatelets and heterostructures for optoelectronic applications. Nano Res. 2017, 10, 1223-1233. [CrossRef]

7. Swarnkar, A.; Marshall, A.R.; Sanehira, E.M.; Chernomordik, B.D.; Moore, D.T.; Christians, J.A.; Chakrabarti, T.; Luther, J.M. Quantum dot-induced phase stabilization of $\alpha-\mathrm{CsPbI}_{3}$ perovskite for high-efficiency photovoltaics. Science 2016, 354, 92-95. [CrossRef] [PubMed]

8. $\quad$ Eaton, S.W.; Lai, M.; Gibson, N.A.; Wong, A.B.; Dou, L.; Ma, J.; Wang, L.-W.; Leone, S.R.; Yang, P. Lasing in robust cesium lead halide perovskite nanowires. Proc. Natl. Acad. Sci. USA 2016, 113, 1993-1998. [CrossRef] [PubMed] 
9. Song, J.; Li, J.; Li, X.; Xu, L.; Dong, Y.; Zeng, H. Quantum dot light-emitting diodes based on inorganic perovskite cesium lead halides $\left(\mathrm{CsPbX}_{3}\right)$. Adv. Mater. 2015, 27, 7162-7167. [CrossRef] [PubMed]

10. Ramasamy, P.; Lim, D.-H.; Kim, B.; Lee, S.-H.; Lee, M.-S.; Lee, J.-S. All-inorganic cesium lead halide perovskite nanocrystals for photodetector applications. Chem. Commun. 2016, 52, 2067-2070. [CrossRef] [PubMed]

11. Saidaminov, M.I.; Almutlaq, J.; Sarmah, S.; Dursun, I.; Zhumekenov, A.A.; Begum, R.; Pan, J.; Cho, N.; Mohammed, O.F.; Bakr, O.M. Pure $\mathrm{Cs}_{4} \mathrm{PbBr}_{6}$ : Highly luminescent zero-dimensional perovskite solids. ACS Energy Lett. 2016, 1, 840-845. [CrossRef]

12. Wang, K.H.; Wu, L.; Li, L.; Yao, H.B.; Qian, H.S.; Yu, S.H. Large-scale synthesis of highly luminescent perovskite-related $\mathrm{CsPb}_{2} \mathrm{Br}_{5}$ nanoplatelets and their fast anion exchange. Angew. Chem. Int. Ed. 2016, 55, 8328-8332. [CrossRef] [PubMed]

13. Zhang, Y.; Saidaminov, M.I.; Dursun, I.; Yang, H.; Murali, B.; Alarousu, E.; Yengel, E.; Alshankiti, B.A.; Bakr, O.M.; Mohammed, O.F. Zero-dimensional $\mathrm{Cs}_{4} \mathrm{PbBr}_{6}$ perovskite nanocrystals. J Phys. Chem. Lett. 2017, 8, 961-965. [CrossRef] [PubMed]

14. Liu, Z.; Bekenstein, Y.; Ye, X.; Nguyen, S.C.; Swabeck, J.; Zhang, D.; Lee, S.-T.; Yang, P.; Ma, W.; Alivisatos, A.P. Ligand mediated transformation of cesium lead bromide perovskite nanocrystals to lead depleted $\mathrm{Cs}_{4} \mathrm{PbBr}_{6}$ nanocrystals. J Am. Chem. Soc. 2017, 139, 5309-5312. [CrossRef] [PubMed]

15. Palazon, F.; Almeida, G.; Akkerman, Q.A.; De Trizio, L.; Dang, Z.; Prato, M.; Manna, L. Changing the dimensionality of cesium lead bromide nanocrystals by reversible postsynthesis transformations with Amines. Chem. Mater. 2017, 29, 4167-4171. [CrossRef] [PubMed]

16. Palazon, F.; Urso, C.; De Trizio, L.; Akkerman, Q.; Marras, S.; Locardi, F.; Nelli, I.; Ferretti, M.; Prato, M.; Manna, L. Postsynthesis Transformation of insulating $\mathrm{Cs}_{4} \mathrm{PbBr}_{6}$ nanocrystals into bright perovskite $\mathrm{CsPbBr}_{3}$ through physical and chemical extraction of CsBr. ACS Energy Lett. 2017, 2, 2445-2448. [CrossRef] [PubMed]

17. Quan, L.N.; Quintero-Bermudez, R.; Voznyy, O.; Walters, G.; Jain, A.; Fan, J.Z.; Zheng, X.; Yang, Z.; Sargent, E.H. Highly emissive green perovskite nanocrystals in a solid state crystalline matrix. Adv. Mater. 2017, 29, 1605945. [CrossRef] [PubMed]

18. Wu, L.; Hu, H.; Xu, Y.; Jiang, S.; Chen, M.; Zhong, Q.; Yang, D.; Liu, Q.; Zhao, Y.; Sun, B. From nonluminescent $\mathrm{Cs}_{4} \mathrm{PbX}_{6}(\mathrm{X}=\mathrm{Cl}, \mathrm{Br}, \mathrm{I})$ nanocrystals to highly luminescent $\mathrm{CsPbX}_{3}$ nanocrystals: water-triggered transformation through a CsX-stripping mechanism. Nano Lett. 2017, 17, 5799-5804. [CrossRef] [PubMed]

19. Li, J.; Zhang, H.; Wang, S.; Long, D.; Li, M.; Guo, Y.; Zhong, Z.; Wu, K.; Wang, D.; Zhang, T. Synthesis of all-inorganic $\mathrm{CsPb}_{2} \mathrm{Br}_{5}$ perovskite and determination of its luminescence mechanism. RSC Adv. 2017, 7, 54002-54007. [CrossRef] 